\title{
Physico-chemical and emission characterization of emulsified biodiesel/diesel blends
}

\begin{abstract}
Biodiesel/diesel blends (BDB) were prepared using different biodiesel percentages (10, 15 and 20\% v/v) namely B10, B15 and B20, respectively. A high energy emulsification method was employed for this purpose. An engine test bed was utilized to combust the emulsion in order to investigate emission gas concentrations such as $\mathrm{CO}, \mathrm{NOx}, \mathrm{CO}_{2}, \mathrm{O}_{2}$ and smoke. The emission concentrations of $\mathrm{NOx}$ and $\mathrm{O}_{2}$ were decreased with increasing biodiesel concentration. However, the emission of $\mathrm{CO}_{2}$ was increased with the increasing amounts of water. The highest concentration of NOx was found for B15. The physicochemical properties of BDB emulsion fuel in terms of viscosity and calorific value were also measured and investigated. Furthermore, biodiesel showed the highest viscosity compared to diesel and BDB fuels. The viscosity of BDB fuels was increased from B10 to B20. The increasing biodiesel concentration showed a decrease in calorific value. Hence, emulsified biodiesel fuel is a promising alternative fuel for reducing harmful emissions.
\end{abstract}

Keyword: Biodiesel/diesel blend; Emulsification; Emission gas concentration; Physicochemical properties; Environmental fuel 